\title{
ANTECEDENTS OF LOCUS OF CAUSALITY ATTRIBUTIONS FOR DESTRUCTIVE ACTS IN DISTRIBUTION CHANNELS
}

\author{
Hadi Eslami \\ Assistant Professor of Marketing \\ Faculty of Business, University of New Brunswick \\ 100 Tucker Park RD, Saint John, NB, E2L 4L5 Canada \\ Voice: 506-648-5848 Facsimile: 905-521-8995 \\ Email: h.eslami@unb.ca \\ Manish Kacker* \\ Associate Professor, Marketing \\ DeGroote School of Business, McMaster University \\ 1280 Main St. W. Hamilton, ON, L8S-4M4 Canada \\ Voice: 905-525-9140 x 21658 Facsimile: 905-521-8995 \\ Email: mkacker@mcmaster.ca \\ Jonathan D. Hibbard \\ Assistant Professor of Marketing \\ Questrom School of Business, Boston University \\ 595 Commonwealth Avenue, Boston, MA 02215 USA \\ Voice: 617-353-4411 \\ Email: jhibbard@bu.edu
}

January, 2019

* Corresponding author.

We are grateful for feedback received from the editors and reviewers as well as from the participants at the 2017 SMA Retail Symposium on Consumer and Retailer Views on the Distribution of Goods and Services and other presentations of this paper. This research was supported by the Social Sciences and Humanities Research Council of Canada. 


\section{ANTECEDENTS OF LOCUS OF CAUSALITY ATTRIBUTIONS FOR DESTRUCTIVE ACTS IN DISTRIBUTION CHANNELS}

Destructive acts in distribution channels are actions by firms that have a significant adverse impact on the viability or functioning of channel members. Understanding an affected channel member's locus of causality attributions for a destructive act can help the initiating firm determine when, where and how to proactively mitigate the adverse consequences of the act. We incorporate insights from interdependence and attribution theories to develop a theoretical framework of antecedents of locus of causality for such acts. We empirically evaluate our hypotheses using survey data from key informants on both sides of supplier-retailer dyads for a Fortune 500 company. We find that interdependence structure, perceived intensity and perceived frequency of destructive acts have implications for causal attributions made by the affected firm (retailer). Further, we find evidence for the impact of relationship quality on causal attributions (including the role it plays in amplifying the effects of other antecedents).

KEYWORDS: Distribution channels, Interdependence theory, Destructive Acts, Causal attributions, Retailing, Interorganizational relationships. 


\section{ANTECEDENTS OF LOCUS OF CAUSALITY ATTRIBUTIONS FOR DESTRUCTIVE ACTS IN DISTRIBUTION CHANNELS}

\section{Introduction}

Technological changes have resulted in dynamic and turbulent environments for many businesses and their distribution channels. Often, to exploit promising opportunities and respond to emergent threats, a firm undertakes actions (e.g., adding a direct channel) that may hurt existing channel members (Ganesan, George, Jap, Palmatier, \& Weitz, 2009). Hibbard, Kumar, and Stern (2001) define a destructive act (DA) as a firm's action that has a significant adverse impact on the viability or functioning of exchange partners in its distribution channels. Existing channels research has largely focused on the negative consequences of DAs in interorganizational relationships (e.g., Ganesan, Brown, Mariadoss, \& Ho, 2010).

Extant distribution channels research confirms that adversely affected partners engage in attributing locus of causality for a DA prior to their reactions to such an act. Hibbard et al. (2001) conclude that whether a firm, impacted by a DA, attributes locus of causality for the act to relatively benign (e.g., itself or the external environment) or relatively damaging (the firm that initiates the act) sources has significant implications for subsequent relationship quality and performance. Given the importance of locus of causality attributions ${ }^{1}$ for better understanding interorganizational conflict and conflict responses (Kaufmann \& Stern 1988), continuity (Wang, Cheng, Craighead \& Li, 2018) and shaping the subsequent behavior of the firm (Frazier, 1983),

\footnotetext{
${ }^{1}$ We draw mainly from research on attribution theory (Kelley \& Michela, 1980) and applications in channels (e.g. Hibbard et al., 2001; Scheer \& Stern, 1992) and management research (e.g., Park, Park, \& Ramanujam, 2018)) which focus on the locus of causality attributions. Two other causal dimensions described by Weiner (1985) stability and controllability - are outside the scope of this study. We are grateful to an anonymous reviewer for highlighting this issue. For simplicity and expositional convenience, we hereafter use the term "causal attribution" to reflect the locus of the causality attribution.
} 
the relative paucity of knowledge about factors that influence to whom or what an affected firm attributes the cause of the DA is surprising. The answer to this question yields key managerial implications as well - First, it can help a supplier design and manage its interorganizational relationships with its retailers through proactive interventions to increase the likelihood of benign causal attributions by the latter. Second, it can create more flexibility for suppliers to undertake DAs necessitated by external business imperatives. Finally, it can reduce the time and resources needed to repair the probable damage to interorganizational relationships caused by DAs. We identify and examine antecedents of causal attributions for DAs in distribution channels. Specifically, we shed light on how variations in causal attributions by independent retailers - for DAs initiated by their focal suppler — may be directly and interactively explained by their interdependence structure (in terms of total dependence and dependence asymmetry) with the focal supplier prior to the DA, the quality of their relationship with the focal supplier prior to the DA, as well as their perceptions of different dimensions (intensity and frequency) of the DA. With this knowledge, a supplier can efficiently identify which of its channel partners are likely to make damaging causal attributions and undertake effective interventions to mitigate their concerns and reduce their likelihood of making adverse causal attributions.

We use a behavioral-based approach (Watson, Worm, Palmatier, \& Ganesan, 2015) and draw from extant interorganizational research in marketing, organization theory, and social psychology to develop a theoretical framework of antecedents of causal attributions for destructive acts. Within these literatures, we rely particularly on the theoretical lens of interdependence theory (Kumar, Scheer, \& Steenkamp, 1995; Kumar, 2005; Scheer, Miao, \& Palmatier, 2015; Wang \& Jap, 2017). Regarding interdependence structure, Kumar (2005) notes key differences between dependence-based and punitive capability-based views of power in 
relationships. Scheer et al. (2015) distinguish between dependence and interdependence-based perspectives. We adopt the interdependence-based view of power ${ }^{2}$ and draw on the work of Emerson (1962), Lawler and Bacharach (1987), and subsequent applications and extensions of this perspective to develop our theoretical framework. We also draw on attribution theory (e.g., Anand \& Stern, 1985; Bradbury \& Fincham, 1990; Kelley \& Michela, 1980; Park, Park, \& Ramanujam, 2018; Scheer \& Stern, 1992; Selnes \& Gønhaug, 2000) to link interdependence, relationship quality and DA dimensions to causal attributions. We empirically evaluate our hypotheses using dyadic, multiple informant survey data collected from the distribution channel of a Fortune 500 firm.

We find that higher levels of total dependence are associated with significantly lower levels of retailer's causal attributions to the supplier for the supplier's DA. As dependence asymmetry increases, a retailer is less likely to make relatively benign causal attributions (to self or the external environment) and, when the supplier is relatively dependent, a retailer is more likely to attribute the DA to the supplier. We also find that a retailer's causal attributions are influenced by its perceptions of the intensity and frequency of the supplier's DAs - when the perceived intensity or frequency is high, a retailer is more likely to make damaging causal attributions and less likely to make benign ones. Finally, we find evidence for the key role played by relationship quality between the supplier and retailer prior to the DA: it reduces causal attribution to self or the supplier as well as amplifies effects of other constructs (e.g., total dependence and intensity and frequency of DAs) on some causal attributions.

\section{Conceptual Framework: Causal Attributions for Destructive Acts}

\footnotetext{
${ }^{2}$ Our conceptualizations of 'total dependence' and 'dependence asymmetry' are similar to the conceptualizations of 'total interdependence' and 'interdependence asymmetry' in Kumar et al. (1995) and Scheer et al. (2015).
} 
We draw on Kelley and Michela (1980) to develop our theoretical model of antecedents of causal attributions. They describe three classes of antecedents - motivation, beliefs, and information. We consider the interdependence structure of the exchange relationship to be a key driver of a retailer's motivation in making causal attributions. This reflects Rusbult and Van Lange's (2003) insights on the importance of interdependence structure (e.g. mutuality and level) in providing a better circumstance-based understanding of interactions and attributions. Kelley and Michela (1980) note that prior beliefs impact causal attributions through their implications for baseline expectations about the actors and the possibility of occurrence of an action in a particular situation. We conceptualize these beliefs and baseline expectations through the construct of prior relationship quality. Finally, Kelley and Michela (1980) indicate that information about the action is used by the affected entity to infer intentions of the initiating entity and make causal attributions. We conceptualize information in terms of dimensions of the destructive act - specifically, the intensity and the frequency of destructive actions undertaken by the supplier. Our conceptual framework is summarized in Figure 1.

\section{Insert Figure 1 about here}

\subsection{Destructive Acts}

Destructive acts in distribution channels have a significant adverse impact on the viability or functioning of the affected channel partner. They can be considered as a type of transformational relationship event (Harmeling, Palmatier, Houston, Arnold, \& Samaha, 2015) and they encompass a wide range of actions (e.g., for a supplier, DAs can include the renegotiation and alteration of exchange terms with channel partners, withdrawal of a popular product line from a downstream channel member, addition of new channel members or channels 
or any other changes that increase intrabrand competition for existing downstream channel members). DAs can be categorized in terms of whether the act is largely motivated by extradyadic factors (with harm to the focal relationship reflecting collateral damage rather than being the primary motivation for the act) or whether the act is primarily driven by intra-dyadic factors (where the primary intent may be to improve, exploit or punish the affected channel member). Further, the latter may include not only transparent, overt acts but also acts of opportunism that reflect "self-interest seeking with guile" (Williamson, 1985, page 47).

The importance of studying DAs is reinforced by the finding that managing and mitigating the consequences of negative actions is more crucial than the accumulation of positive actions for the long-term well-being of relationships (Baumeister, Bratslavsky, Finkenauer, \& Vohs, 2001). An understanding of factors influencing an affected party's causal attributions in the wake of a DA by another party can help the latter determine when, where and how to intervene to mitigate adverse attributions and, therefore, limit their damaging consequences.

\subsection{The Nature of Causal Attributions}

In social psychology research, considerable attention has been given to the role of causal attributions in distressed relationships (e.g., Bradbury \& Fincham, 1990). Insights into causal attributions have been driven by attribution theories (Kelley \& Michela, 1980). Attribution research is concerned with causality inferences: how people engage in causality inferences, what they infer, and what the consequences of their causality inferences are. Kelley and Michela (1980) distinguish between theoretical perspectives on the antecedents and the consequences of causality attributions. With regard to antecedents, information about behavior and the 
circumstances of the destructive act are used to make causal attributions to internal or external factors (Kelley, 1967; Thibaut \& Riecken, 1955).

Attribution theory (Kelley and Michela, 1980) provides relevant insights for business contexts (e.g., Selnes \& Gønhaug, 2000; Scheer \& Stern, 1992). Selnes and Gønhaug (2000) note that attribution theory can facilitate an understanding of positive and negative attitudes toward a supplier and that "It follows from attribution theory that negative deviance from what is promised, particularly in routine or ordinary would be attributed to the supplier. Negative experiences may evoke affective responses of negative valence (e.g., anger)."

We view internal and external causal attributions for DAs in terms of attributions to self (retailer), partner (supplier), and external circumstances - this reflects a typology that has been previously used in the distribution channels literature (e.g. Scheer \& Stern, 1992 and Hibbard et al., 2001). Drawing from interdependence theory (Kumar et al., 1995) and social psychology research (Rusbult \& Van Lange, 2003), we consider the interdependence structure of the exchange relationship between the supplier and retailer to be a key driver of the latter's causal attributions. By the same token, we theorize dimensions of the DA - specifically, the perceived intensity and frequency of destructive actions undertaken by the supplier - as antecedents of causal attributions. Finally, we recognize that relationship quality consists of multiple dimensions (Jap, Manolis, \& Weitz, 1999) and conceptualize it to consist of trust (Anderson \& Narus, 1990), commitment (Kumar et al, 1995), and socialization (Heide, 1994) between the partners. We view prior relationship quality to reflect the baseline expectation that a retailer has made over time about its focal supplier prior to the supplier's DA. Thus, prior relationship quality impacts a retailer's causal attribution in the wake of a supplier's DA and plays a key role in moderating the effects of other antecedents on causal attributions. 


\subsection{Interdependence}

The implications of interdependence for causal attributions can be drawn from extant research that examines the consequences of power and dependence in channel relationships (e.g. Frazier, Gill, \& Kale, 1989). This conceptualization of interdependence has been refined to incorporate the magnitude and direction of each channel member's dependence on the other

(e.g., Buchanan, 1992). This approach disentangles the effect of two dimensions of power and dependence - total dependence and dependence asymmetry - from each other in distribution channel relationships (Kumar et al., 1995; Lusch \& Brown, 1996). While total dependence refers to the sum of each firm's dependence on its partner, dependence asymmetry is reflected by the difference between the firm's dependence on its partner and the partner's dependence on the firm (Kumar et al., 1995). This stream of the interdependence literature has posited and found divergent effects of total dependence and dependence asymmetry on channel members' attitudes and behaviors (e.g., Kumar et al., 1995; van Bruggen, Kacker, \& Nieuwlaat, 2005). In keeping with this line of thinking, we posit that total dependence and dependence asymmetry will have different effects on the causal attributions for DAs.

\subsection{The Effect of Total Dependence on Causal Attributions}

Social psychology and sociology research suggests that the interdependence structure of a relationship influences the causal attributions for destructive acts. Attribution theory research (Kelley \& Michela, 1980) posits that the dependence of a person on another person is an element of motivation (one of the three classes of antecedents of causal attributions). A high level of mutual dependence yields patterns of cognition that reduce the feeling of insecurity between partners and increases the longevity of relationships (Murray, Holmes, \& Griffin, 1996; Rusbult, 
Van Lange, Wildschut, Yovetich, \& Verette, 2000). Lawler and Bacharach (1987) conclude that greater total power results in lower conflict in the relationship - thus, in a relationship with greater total power (that is, greater total dependence), an affected actor is likely to make a causal attribution that is less likely to result in conflict. Lawler and Yoon (1996) find that greater total power in a relationship promotes exchanges that arouse positive emotions, creates perceptions of the relation as a cohesive unit and increases actors' tendencies to stay in the exchange relation despite the existence of attractive alternatives. In these circumstances, an actor is less likely to make a causal attribution that adversely impacts this cohesion. As total dependence increases, the supplier and the retailer have a greater incentive to stay in the relationship, avoid manifest dysfunctional conflict, eschew retaliation and ensure successful relationship outcomes (Buchanan, 1992; Kumar et al., 1995). In such situations, channel members develop flexible adjustment processes (Heide, 1994). Thus, when total dependence is higher, the retailer is likely to make a causal attribution for the DA that minimizes the potential for manifest conflict and ensures the continuation of the relationship with the supplier - this implies a causal attribution to self or to an external factor rather than to the supplier. Therefore, we posit:

$\mathrm{H}_{1 \mathrm{a}}$ : All else being equal, as the level of total dependence in the relationship increases, the retailer is more likely to attribute the cause of a supplier's destructive act to itself.

$\mathrm{H}_{1 \mathrm{~b}}$ : All else being equal, as the level of total dependence in the relationship increases, the retailer is less likely to attribute the cause of a supplier's destructive act to the supplier.

$\mathrm{H}_{1 \mathrm{c}}$ : All else being equal, as the level of total dependence in the relationship increases, the retailer is more likely to attribute the cause of a supplier's destructive act to the external environment.

\subsection{The Effect of Dependence Asymmetry on Causal Attributions}

Extant research in social psychology and sociology contains implications for the effect of dependence asymmetry on causal attributions. Greater levels of dependence asymmetry tend to 
activate cognition processes of the relatively dependent partner along with adaptation to reduce its vulnerability (Rusbult \& Van Lange, 2003). Lawler and Yoon (1996) find that greater power asymmetry results in lower relational cohesion. Lawler, Ford, and Blegen (1988) indicate that relationships characterized by greater asymmetry in dependence (keeping total dependence constant) are characterized by relatively higher levels of aggression and conflict for all parties. The relatively less dependent party has few incentives to suppress conflict. The relatively more dependent party consequently anticipates attacks regardless of its own behavior and is just as likely to initiate conflict through a preemptive strike. Under these conditions, the affected party is less likely to refrain from making the causal attribution to the party that initiated the DA. Park et al. (2018) propose that when an organization has higher relative power, it is more likely to privately and publicly blame its organizational partner. Distribution channel relationships characterized by greater power asymmetry have been found to be positively associated with the use of coercive influence strategies (Frazier et al., 1989), channel conflict (Kumar et al., 1995), aggressive, distributive conflict resolution strategies (Dant \& Schul, 1992), and severe contract enforcement (Antia \& Frazier, 2001). These relationships tend to be less stable and more dysfunctional (Anderson \& Weitz, 1989). Therefore, regardless of whether the retailer is relatively more or less powerful, it is more likely to attribute the DA to the supplier as dependence asymmetry increases. Furthermore, relationships with an asymmetrical dependence structure are characterized by unidirectional, direct, formal, lower-frequency patterns of communications (Mohr \& Nevin, 1990) - this reduces the likelihood that a supplier can, in the normal course of communications, effectively explain and justify the DA to a retailer and influence it to attribute causality away from the supplier. Therefore, we posit: 
$\mathrm{H}_{2 \mathrm{a}}$ : $\quad$ All else being equal, as the level of dependence asymmetry in the relationship increases, the retailer is less likely to attribute the cause of a supplier's destructive act to itself.

$\mathrm{H}_{2 \mathrm{~b}}$ : All else being equal, as the level of dependence asymmetry in the relationship increases, the retailer is more likely to attribute the cause of a supplier's destructive act to the supplier.

$\mathrm{H}_{2 \mathrm{c}}$ : $\quad$ All else being equal, as the level of dependence asymmetry in the relationship increases, the retailer is less likely to attribute the cause of a supplier's destructive act to the external environment.

\subsection{The Effect of Prior Relationship Quality on Causal Attributions}

Kelley and Michela (1980) note that preexisting beliefs are important antecedents of causal attributions. The perceiver's expectations about an actor's behavior are a function of the perceiver's beliefs shaped by the actor's past behavioral consistency. Thus, if the actor's behaviors are consistent with what the perceiver expects based on its prior experience in relationship with the actor, then they are likely to be attributed to the actor (Selnes \& Gønhaug, 2000); if the behaviors are unexpected by the perceiver, they are likely to be attributed to external circumstances. Thus, one possible manifestation of high supplier-retailer relationship quality prior to the supplier's DA is the retailer's attribution of the DA to external factors rather than its supplier. In this regard, Anand (1987) notes that when two partners are "close", the party making the causal attribution typically attributes negative events to situational factors rather than directly to the partner. Park et al. (2018) argue that the higher the relational coordination between an organization and its partner, the less likely the organization is to resort to private blame shifting. In examining the effects of causal attributions in conflictual commercial exchange relationships, Kaufmann and Stern (1988) found that the existence of a relational (as opposed to a discrete) exchange is more likely to lead to greater tolerance of conflict behavior if the conflict is attributed to factors beyond the parties' control. This indicates that, in relationships 
characterized by relatively higher relationship quality, a retailer may be more likely to attribute motives for a supplier's DA to external circumstances. Therefore, we posit:

$\mathrm{H}_{3 \mathrm{a}}$ : All else being equal, as the retailer's perception of the prior relationship quality with the supplier increases, the retailer is less likely to attribute the cause of a supplier's destructive act to itself.

$\mathrm{H}_{3 \mathrm{~b}}$ : $\quad$ All else being equal, as the retailer's perception of the prior relationship quality with the supplier increases, the retailer is less likely to attribute the cause of a supplier's destructive act to the supplier.

$\mathrm{H}_{3 c}$ : All else being equal, as the retailer's perception of the prior relationship quality with the supplier increases, the retailer is more likely to attribute the cause of a supplier's destructive act to the external environment.

\subsection{The Effect of the Intensity and Frequency of the Destructive Act on Causal Attributions}

Causal attributions for an act are influenced by the affected entity's perceived comparison of the action to other actions that the actor may have alternatively taken (Kelley \& Michela, 1980). The principle of non-common effects impacts the perceiver's causal inferences about the actor's intentions (Jones \& Davis, 1965). Thus, a retailer's assessment of the perceived intensity and frequency of the DA can be formed by comparing the actual DA with what the retailer may have expected of the supplier. The same act may create different perceived intensity and frequency in different retailers, all else being equal. We expect that if the DA is more intense, it is likely to reflect a greater violation of the psychological contract and reduce incentives to stay in and further invest in the relationship (Kim, Hibbard, \& Swain, 2011). Under these circumstances, the retailer is less likely to attribute it to a benign source such as itself or the external environment (Hibbard et al., 2001). Instead, it is more likely to hold the supplier directly responsible for it. In their conceptual examination of blame shifting, Park et al. (2018) propose that the higher the magnitude of the failure, the more likely is an organization to resort to public and private blame shifting - this suggests that, when a retailer's perceived intensity of a DA by the supplier is high, it is more likely to attribute the DA to the supplier. Similarly, if the supplier 
has exhibited a historical pattern of engaging in such DAs, a retailer is less likely to overlook the supplier's DA and attribute it to itself or external factors (rather than the supplier) in the interest of safeguarding the relationship. Westberg, Stavros, and Wilson (2011) propose a positive association between the frequency of negative behaviors and attribution of the behavior to the entity engaging in it. We submit that when the frequency of DAs by the other party is relatively high, the affected entity may attribute the act to the other party. Therefore, we hypothesize that:

$\mathrm{H}_{4 \mathrm{a}}$ : All else being equal, as the retailer's perception of the intensity of the supplier's destructive act increases, the retailer is less likely to attribute the cause of a supplier's destructive act to itself.

$\mathrm{H}_{4 \mathrm{~b}}$ : All else being equal, as the retailer's perception of the intensity of the supplier's destructive act increases, the retailer is more likely to attribute the cause of a supplier's destructive act to the supplier.

$\mathrm{H}_{4 \mathrm{c}}$ : All else being equal, as the retailer's perception of the intensity of the supplier's destructive act increases, the retailer is less likely to attribute the cause of a supplier's destructive act to the external environment.

$\mathrm{H}_{5 \mathrm{a}}$ : All else being equal, as the retailer's perception of the frequency of the supplier's destructive acts increases, the retailer is less likely to attribute the cause of a supplier's destructive act to itself.

$\mathrm{H}_{5 b}$ : All else being equal, as the retailer's perception of the frequency of the supplier's destructive acts increases, the retailer is more likely to attribute the cause of a supplier's destructive act to the supplier.

$\mathrm{H}_{5 \mathrm{c}}$ : All else being equal, as the retailer's perception of the frequency of the supplier's destructive acts increases, the retailer is less likely to attribute the cause of a supplier's destructive act to the external environment.

\subsection{The Interactive Effect of Total Dependence and Prior Relationship Quality on Causal Attributions}

In a preceding section, we hypothesized the simple effect of total dependence on the causal attributions $\left(\mathrm{H}_{1 \mathrm{a}}, \mathrm{H}_{1 \mathrm{~b}}\right.$, and $\left.\mathrm{H}_{1 \mathrm{c}}\right)$. Now, we consider how this effect is amplified by the level of prior relationship quality. When total dependence is high, both parties are motivated to stay in the relationship and refrain from actions (including causal attributions) that could lead to manifest dysfunctional conflict. The likelihood that, under these circumstances, a retailer will 
choose to attribute causality to itself or the external environment (rather than to the supplier)

should be greater when prior relationship quality is higher since the latter reflects more positive retailer expectations and beliefs about the supplier. Thus, we posit:

$\mathrm{H}_{6 \mathrm{a}}: \quad$ All else being equal, the positive effect of the level of total dependence in the relationship on the likelihood that the retailer will attribute the cause to itself will be greater for higher levels of prior relationship quality.

$\mathrm{H}_{6 \mathrm{~b}}$ : All else being equal, the negative effect of the level of total dependence in the relationship on the likelihood that the retailer will attribute the cause to the supplier will be greater for higher levels of prior relationship quality than for lower levels of prior relationship quality.

$\mathrm{H}_{6 c}$ : All else being equal, the positive effect of the level of total dependence in the relationship on the likelihood that the retailer will attribute the cause to the external environment will be greater for higher levels of prior relationship quality.

\subsection{The Interactive Effect of Dependence Asymmetry and Prior Relationship Quality on Causal Attributions}

Higher levels of prior relationship quality imply that the affected actor views the initiating actor's past behavior to be more prosocial and has higher expectations about its benevolent future behavior (Agnew, Van Lange, Rusbult, \& Langston, 1998). In such situations, the greater perceived violation of the psychological contract will amplify the impact of higher levels of dependence asymmetry (and the underlying higher levels of aggression and conflict) on causal attributions. This yields the following hypotheses:

$\mathrm{H}_{7 \mathrm{a}}$ : All else being equal, the negative effect of the level of dependence asymmetry in the relationship on the likelihood that the retailer will attribute the cause to itself will be greater for higher levels of prior relationship quality.

$\mathrm{H}_{7 \mathrm{~b}}$ : $\quad$ All else being equal, the positive effect of the level of dependence asymmetry in the relationship on the likelihood that the retailer will attribute the cause to the supplier will be greater for higher levels of prior relationship quality.

$\mathrm{H}_{7 \mathrm{c}}$ : $\quad$ All else being equal, the negative effect of the level of dependence asymmetry in the relationship on the likelihood that the retailer will attribute the cause to the external environment will be greater for higher levels of prior relationship quality. 


\subsection{The Interactive Effect of Destructive Act Dimensions (Frequency and Intensity) and Prior Relationship Quality on Causal Attributions}

Prior relationship quality reflects the beliefs that the retailer has regarding the supplier. This sets up a baseline level of expectation for the retailer, regarding the future behavior of the supplier. We previously noted that any deviation from the supplier's previous consistent behavior would be attributed by the retailer to the external factors. Further, we posit that when prior relationship quality is high (reflecting the underlying baseline beliefs and expectations about the supplier's intentions and actions being correspondingly elevated), the negative effects of DAs with high levels of intensity or frequency on the retailer's causal attributions will be amplified. Therefore, we hypothesize:

$\mathrm{H}_{8 \mathrm{a}}: \quad$ All else being equal, the negative effect of the retailer's perception of the intensity of the supplier's destructive act on the likelihood that the retailer will attribute the cause to itself will be greater for higher levels of prior relationship quality.

$\mathrm{H}_{8 \mathrm{~b}}$ : All else being equal, the positive effect of the retailer's perception of the intensity of the supplier's destructive act on the likelihood that the retailer will attribute the cause to the supplier will be greater for higher levels of prior relationship quality.

$\mathrm{H}_{8 \mathrm{c}}$ : All else being equal, the negative effect of the retailer's perception of the intensity of the supplier's destructive act on the likelihood that the retailer will attribute the cause to the external environment will be greater for higher levels of prior relationship quality.

$\mathrm{H}_{9 \mathrm{a}}$ : All else being equal, the negative effect of the retailer's perception of the frequency of the supplier's destructive acts on the likelihood that the retailer will attribute the cause to itself will be greater for higher levels of prior relationship quality.

$\mathrm{H}_{9 b}$ : All else being equal, the positive effect of the retailer's perception of the frequency of the supplier's destructive acts on the likelihood that the retailer will attribute the cause to the supplier will be greater for higher levels of prior relationship quality.

$\mathrm{H}_{9 \mathrm{c}}$ : All else being equal, the negative effect of the retailer's perception of the frequency of the supplier's destructive acts on the likelihood that the retailer will attribute the cause to the external environment will be greater for higher levels of prior relationship quality. 


\section{Methodology}

\subsection{Research Context}

We selected the distribution channel of a Fortune 500 manufacturer of consumer durables as the empirical setting for our study. Our choice was driven by the fact that this distribution system had experienced several DAs (as perceived by the participating channel members). This supplier historically used company-owned stores and independent retailers to distribute its products. However, in response to changing end-user preferences, it added a national mass merchandiser to its existing distribution system. This action (as well as other contemporaneous actions of the supplier) was perceived by the independent retailers as destructive to them and their relationship with the supplier. Concerned about channel conflict, the supplier voluntarily supported this research effort. We focus on the independent retailer channel of the company. Concentrating on one supplier (rather than a number of them) gave us some degree of control while allowing for adequate variation in the constructs of interest (e.g., interdependence structure, prior relationship quality, causal attributions).

\subsection{Sample and Data Collection Procedure}

We collected primary survey data from both sides of the dyad - the retailers as well as the supplier. The use of multiple informants is in keeping with the recommendations of Kumar, Stern, and Anderson (1993) and van Bruggen, Lilien, and Kacker (2002). We obtained data from key informants for each retailer on the intensity and frequency of DAs, prior relationship quality, retailer dependence, and relationship age (a control variable). We also collected data from key informants for the supplier about supplier dependence on each retailer. 


\subsubsection{Data Collection from Retailers}

Initially, we received a list of 1200 active, independent retailers from the supplier. This list included the name and position of the key informant for each retailer holding the title of owner, president, or chief executive officer (in $80 \%$ of the cases). We sent these 1200 retailers an informant competency assessment (as suggested by Kumar et al., 1993), two introductory letters, a reply envelope, and the questionnaire. One letter was from a senior executive of the supplier's organization, requesting retailers to cooperate with the study while assuring them that the study was being conducted independently by the researchers. The other letter, from the researchers, promised that individual responses of a retailer would not be revealed to the supplier and provided information about an opportunity to win $\$ 1000$ in a retailer lottery for completed questionnaires. Follow-up questionnaires were mailed to nonrespondents. We were unable to deliver 14 sets of questionnaires. From an effective sample of 1186 retailers, we received responses from 742 retailers, representing a 62.6\% response rate. Following Kumar et al. (1993), we eliminated 7 responses because they did not meet minimum informant competency standards. In addition, we excluded 36 informants because they had an excessive number of missing responses in their completed surveys. Therefore, the final sample consisted of 699 retailers.

\subsubsection{Data Collection from Supplier}

We contacted district managers of the supplier's organization to find appropriate informants associated with each of the 699 retailers in our sample. Due to the limited number of district and sales managers, each informant reported on multiple retailers to maximize the matched pairs. Along with the survey (including questions about the supplier's dependence on a retailer), we included a short questionnaire to assess informant competency, a letter from an executive officer from the supplier's organization and a letter from the researchers ensuring the 
confidentiality of responses. Also, we made follow-up telephone calls to nonrespondents. Of the 699 surveys, 640 were returned from 144 informants, resulting in a response rate of $92 \%$. After scrutinizing individual responses, we eliminated responses from 12 respondents who did not meet the informant competency test. Of the remaining 628 questionnaires, 429 questionnaires (from 118 supplier-side key informants) included responses on supplier dependence.

\subsection{Measures}

We now provide details on our choices (and underlying rationales) for measures used to operationalize our theoretical constructs. The specific scales used appear in Appendix A.

\subsubsection{Total Dependence and Dependence Asymmetry}

Kumar et al. (1995) developed scales to measure retailer and supplier dependence.

However, they collected data for both measures from downstream channel members only. While we based our measures on Kumar et al. (1995), we collected data on dependence from retailers as well as from the focal supplier. Using the additive approach employed by Kumar et al. (1995) and van Bruggen et al. (2005), we measured total dependence as the sum of each party's dependence on the other and dependence asymmetry as the absolute difference between each party's dependence on the other.

We used spline regression (Marsh \& Cormier, 2001) in our empirical analyses to account for whether the direction of dependence asymmetry (that is, whether the retailer or the supplier was the relatively dependent channel member) impacts locus of causality attributions. Kumar et al. (1995), Kumar, Scheer and Steenkamp (1998) and van Bruggen et al. (2005) have used spline regression analysis to examine the effects of dependence asysmmetry in interorganizational exchange relationships. Kumar et al. (1998) note that spline analysis provides more information 
about the nature of the effects of dependence asymmetry. Scheer et al. (2015) advocate the use of spline variables when interdependence asymmetry has theoretical relevance for the constructs and hypotheses being investigated.

Using linear OLS spline regression, we capture the effect of dependence asymmetry when the supplier is relatively more dependent on the retailer as well as the corresponding effect when the retailer is relatively more dependent on the supplier. To this end, we undertook the following procedures based on the approach previously used by Kumar et al. (1995), Kumar et al. (1998) and van Bruggen et. al. (2005):

i. Computing the absolute value of the difference between the retailer dependence and the supplier dependence scores (absolute dependence asymmetry).

ii. Creating two dummy variables: $\mathrm{D}_{1}=1$ if the supplier dependence < retailer dependence and 0 otherwise; $\mathrm{D}_{2}=1$ if the supplier dependence $>$ retailer dependence and 0 otherwise.

iii. Developing 'retailer relative dependence' and 'supplier relative dependence' measures after multiplying $\mathrm{D}_{1}$ and $\mathrm{D}_{2}$ by absolute dependence asymmetry (calculated in i.) respectively.

In line with our conceptualization of relative dependence asymmetry, the above procedure facilitates analysis that splits the effects of dependence asymmetry so that we can assess whether there is a significant difference in the slope when the supplier is relatively dependent compared to when the retailer is relatively dependent. Thus, we are able to examine whether the directional effects of dependence asymmetry between the retailer and the supplier would be different in impacting causal attributions for the DA. 


\subsubsection{Prior Relationship Quality}

In keeping with extant research in marketing (e.g., Anderson \& Narus, 1990; Dwyer \& Oh, 1987; Kumar et al., 1995), we measured prior relationship quality as a higher order construct that includes multiple distinct and commonly used first-order constructs - trust, commitment, and socialization. To control for any possible relationship between the "prior relationship quality' and 'interdependence structure' constructs, we used a corrected estimate method (e.g., van Bruggen et al., 2005). We corrected for the presence of such a relationship by separately regressing prior relationship quality on retailer dependence and supplier dependence. We then used the residuals of these two regression analyses as corrected estimates of retailer and supplier

dependence. Subsequently, we computed total dependence by adding up the corrected scores for retailer dependence and supplier dependence. Similarly, in calculating 'retailer relative dependence' and 'supplier relative dependence', we undertook procedures i to iii (described in the previous sub-section) again, using the corrected scores.

\subsubsection{Intensity and Frequency of Destructive Acts}

Prior to eliciting responses on the intensity and frequency of DAs, we generated a list of the supplier's potential destructive actions by conducting preliminary telephone and in-person interviews with retailers. From the list, we selected four recent supplier actions that were frequently mentioned by retailers as the most damaging to them. Each retailer was asked to choose the action that had the most negative effect on it from these four actions. Retailers also had an opportunity to specify some other supplier action (outside of the list of four DAs) as the most damaging. The retailer's perceptions regarding the intensity and frequency of DAs were then captured separately by a single question each on a seven-point scale. Given the concrete nature of these two constructs, the use of a single item scale is appropriate (Rossiter, 2002). 


\subsubsection{Causal Attributions}

We adapted scales from Bradbury and Fincham (1990) to measure the three types of causal attributions: self, partner, and external. Each of these attributions was measured by three items.

\subsubsection{Control Variable}

It is important to account for systematic variations in a retailer's causal attributions due to factors other than interdependence structure, prior relationship quality, and the perceived intensity and frequency of the DA. Based on the marketing and distribution channels literature (e.g. Kim et al., 2011) we selected age of the relationship as a control variable.

\subsection{Measure Validation}

Following the recommendations of Churchill (1979) and Gerbing and Anderson (1988), we examined reliability and construct validity of the scales to ensure the consistency and accuracy of their measurements. In the first stage, we used the cross-loading analysis technique to check whether measurement items would load on their own designated factors. To that end, exploratory factor analysis (EFA) was conducted (maximum likelihood, oblique rotation) to eliminate items with high cross-loadings. All of our items had significantly larger loadings on their designated factors than on other factors, showing no cross-loading issue.

In the second stage, we employed confirmatory factor analysis (CFA) to assess the adequacy of measurement constructs. To this end, we established our measurement model including both lower order and higher order factors. Consistent with our theoretical conceptualization, prior relationship quality was determined to be a higher-order construct. 
We specified our measurement model by allowing measurement items and lower-order constructs to be loaded on their related factors while correlating higher-order constructs (prior relationship quality, retailer dependence, supplier dependence, attribution to self, attribution to the supplier, and attribution to the external environment). The overall chi-square for the model was significant $\left(\chi^{2}(212) 328.881 ; p<.001\right)$. Goodness-of-fit indices ensure acceptability of the specified model for measuring our constructs - the comparative fit index (CIF; .967), the TuckerLewis index (TLI; .965), the non-normed fit index (NNFI; .922), and the root mean square root of approximation (RMSEA; .036) met recommended values for goodness of fit (Bollen, 1990).

To assess high factor reliability, we used SPSS-Amos 22.0 software to calculate Cronbach's alpha for each of our factors. All composite reliabilities were greater than .70 except for one scale- self-attribution (.68). Thus, we can conclude that our estimations would not be significantly affected by the effect of low reliabilities (consistency). All the factor loadings in our CFA measurement model were significant (t-value $>2$ ) and greater than .5 (except for one loading value of .45) with an average loading of .74. These results support convergent validity of measurement items (Anderson \& Gerbing, 1988). Also, we conducted average variance extracted (AVE) analysis to examine the discriminant validity of our measurement constructs. The square root of average variance extracted for each latent factor was greater than the largest correlation of the factor with any other factors. These results support discriminant validity. The intercorrelations between constructs were significantly below unity $(\mathrm{p}<.001)$, providing additional support for discriminant validity. Information regarding scale reliabilities, correlations, goodness-of-fit statistics, and other descriptive statistics appears in Table 1.

Please insert Table 1 about here 


\subsection{Common Method Bias}

We collected data from the focal supplier and its retailers to calculate interdependence structure (total dependence and dependence asymmetry). Using multiple sources in the process of data collection would decrease the presence of common method bias by improving the reliability of the measure and increasing confidence in the results (Ganesan, 1994). However, we had to collect measures for other core constructs (perceived prior relationship quality, causal attributions, and intensity and frequency of DA) from the same source (retailers) to test our hypotheses. As a result, method factors may bias estimates regarding construct reliability, validity, or any other relationship between two different constructs (Podsakoff, MacKenzie, \& Podsakoff, 2012). In the marketing literature, Bagozzi (1984) cautioned that it is imperative to discover the sources of common method bias and to reduce the threat posed by them. To this end, we used several procedural (MacKenzie \& Podsakoff, 2012) as well as statistical (Podsakoff \& Organ, 1986; Podsakoff et al., 2012) remedies that are described below.

\subsubsection{Procedural Remedies}

In the design stage of the survey, we emphasized clear grammar, easy to understand language and concise measurement in developing items. We guaranteed confidentiality to all respondents to reduce their social desirability bias and clarified that there were no wrong or right answers for items. We employed different (rather than identical) scale formats (e.g., we used a list with yes/no format for eliciting the DA and a 7-point Likert scale for measuring single item and multi-item constructs). More specifically, consistent with the recommendations by MacKenzie and Podsakoff (2012), we used a clear process to assist the retailers in recalling the information necessary and related to DA dimensions. To this end, we first asked retailers to select whether the four actions listed in the survey had any negative impact on them. Retailers 
were also given the opportunity to write in some other supplier action that had a negative effect. Next, we asked each retailer to select the supplier's act that they believe had the most negative effect on it. They were then instructed to answer questions regarding DA intensity and severity while keeping in mind the specific negative act they had identified. These steps facilitate temporal retrieval of the necessary information (MacKenzie \& Podsakoff, 2012) for retailers to respond to the questions accurately. In addition, we used both positive and negative formats for items to proactively control for acquiescence and disacquiescence bias (Podsakoff et al., 2012).

\subsubsection{Statistical Remedies}

In addition to the above procedural remedies, we conducted two post hoc statistical tests to verify that common method bias would not be a problem in inflating or deflating our reliability, validity, and other estimates.

First, we conducted the Harman single factor test on all variables measured by a common method (Podsakoff, MacKenzie, Lee \& Podsakoff, 2003). Submitting all measurement items collected from retailers to principal component analysis, the results show that no single factor was extracted and that the variance accounted for by one factor was $18.77 \%$, substantially below the threshold level of 50\% (Fuller, Simmering, Atinc, Atinc, \& Babin, 2016). Thus, the Harman single factor test did not indicate the presence of common method bias.

Second, we employed the unmeasured latent method factor (ULMF) technique (Podsakoff et al., 2012) to further check for the presence of common method bias. Since we have both second-order and first-order constructs, we used two different models in applying the ULMF technique. In the first model, measurement items of trust, commitment, and socialization (as the first-order constructs) were specified to also load on an unmeasured latent factor. Also, relationship quality was specified as a second-order construct reflecting trust, commitment, and 
socialization. Next, we compared the model fit with the common latent factor $\left(\chi^{2}(23)=33.203 ; \mathrm{p}\right.$ $>.05)$ with the model fit without the common latent factor $\left(\chi^{2}(24)=27.123 ; p>.1\right)$. The results of model fit comparison (comparison of models' chi-square) indicate that including the method factor did not change the model significantly. As a result, the latent method factor did not change the model significantly. In the second model, we added the method factor to a model with all other first order constructs measured from retailers. More specifically, we loaded all measurement items both on the latent method factor and on their representative factors. Similarly, we compared the model fit results with the method factor $(\chi 2(47)=102.972 ; \mathrm{p}<.01)$ and those without the method factor $\left(\chi^{2}(48)=105.373 ; \mathrm{p}<.01\right)$. The results of the model fit comparison (comparison of models' chi-square values) indicate that including the method factor did not change the model significantly. These models show that methodological artifacts may not influence our estimates, providing evidence that common method bias is not a substantial concern.

\section{Results}

We used moderated spline regression to empirically evaluate our hypotheses ${ }^{3}$. Also, in keeping with the recommendations of Aiken and West (1991), we mean-centered the data. Our results indicate that the highest variance inflation (VIF) was 1.44 across all three dependent variables, well below the threshold of 10 (Netter, Wasserman, \& Kutner, 1990).

As mentioned earlier, due to the limited number of district and sales managers, 118 key informants from the supplier side reported on survey questions regarding supplier's dependence on 429 retailers. Since one supplier informant may provide responses on multiple retailers, this

\footnotetext{
${ }^{3}$ We also used Structural Equation Modeling (SEM) analysis to check the simultaneous effects of antecedents (allowing interactions) on our multiple dependent variables. The results of both moderated regression and SEM analyses are similar and, therefore, we report the regression results in Table 2.
} 
may raise the issue of clustering error. As a result, we conducted regression with clustered data to ensure the regression results are consistent and robust. Since the results of OLS regression correcting for clustered error are not significantly different from original estimates, it indicates that our original regression results are robust. Therefore, we reported the original estimates.

The results of our moderated spline regression analyses are contained in Table 2. Overall, with the exception of $\mathrm{H}_{7}$, we found complete or partial support for our hypotheses.

\section{Please insert Table 2 about here}

\subsection{Effects of Interdependence Structure on Causal Attributions}

Our empirical results partially support $\mathrm{H}_{1}$. We hypothesized that as the level of total dependence in a channel relationship increases, retailers are less likely to attribute the DA to the supplier $\left(\mathrm{H}_{1 \mathrm{~b}} ; b=-.08, p<.01\right)$. We did not find support for $\mathrm{H}_{1 \mathrm{a}}$ and $\mathrm{H}_{1 \mathrm{c}}-$ our results indicated statistically nonsignificant effects for causal attribution to self $\left(\mathrm{H}_{1 \mathrm{a}} ; b=.02 ; p<.15\right)$ and the external environment $\left(\mathrm{H}_{1 \mathrm{c}} ; b=.02 ; p<.25\right)$.

We found substantial backing for $\mathrm{H}_{2}$. We employed spline regression analysis to examine whether the effect of dependence asymmetry on causal attributions for DAs depends on the direction of asymmetry. Using spline regression analysis facilitates a better understanding of whether the slope of dependence asymmetry varies significantly when the retailer is relatively more or relatively less dependent on the supplier. As reported in Table 2, the results of the spline regression analyses fully support $\mathrm{H}_{2 \mathrm{a}}$ and $\mathrm{H}_{2 \mathrm{c}}$ and partially support $\mathrm{H}_{2 \mathrm{~b}}$. As a retailer's relative dependence on the supplier in a channel relationship increases, it is less likely to attribute causality to self $\left(\mathrm{H}_{2 \mathrm{a}} ; b=-.07, p<.08\right)$ and more likely to the external environment $\left(\mathrm{H}_{2 \mathrm{c}} ; b=-.13\right.$, $p<.05)$. There is no statistically significant support for $\mathrm{H}_{2 \mathrm{~b}}$ regarding the effect of retailer relative 
dependence on causal attribution to the supplier $\left(\mathrm{H}_{2 \mathrm{~b}} ; b=.06, p<.19\right)$; however, $\mathrm{H}_{2 \mathrm{~b}}$ is supported when the supplier is relatively dependent on the retailer $\left(\mathrm{H}_{2 \mathrm{~b}} ; b=.10, p<.07\right)$. We also found that as the level of supplier relative dependence on retailers in a channel relationship increases, retailers are less likely to attribute to self $\left(\mathrm{H}_{2 \mathrm{a}} ; b=-.09, p<.04\right)$ and the external environment $\left(\mathrm{H}_{2 \mathrm{c}}\right.$; $b=-.11, p<.09)$.

\subsection{Effects of Prior Relationship Quality on Causal Attributions}

We find partial support for $\mathrm{H}_{3}$ in our empirical results. As the level of prior relationship quality in a channel relationship increases, retailers are less likely to attribute the DA to self $\left(\mathrm{H}_{3 \mathrm{a}}\right.$; $b=-.08, p<.04)$ or the supplier $\left(\mathrm{H}_{3 \mathrm{~b}} ; b=-.125, p<.02\right)$. We find no significant support for the posited effect on attribution to the external environment $\left(\mathrm{H}_{3 c} ; b=.08, p<.13\right)$.

\subsection{Effects of Destructive Act Dimensions on Causal Attributions}

Our results reflect comprehensive support for $\mathrm{H}_{4}$ and $\mathrm{H}_{5}$. We find statistically significant support for the hypothesized effects of perceived DA intensity on attributions to self $\left(\mathrm{H}_{4 a} ; b=-\right.$ $.08, p<.01)$, the supplier $\left(\mathrm{H}_{4 \mathrm{~b}} ; b=.08, p<.02\right)$ and the external environment $\left(\mathrm{H}_{4 \mathrm{c}} ; b=-.20, p<.01\right)$. Similarly, we observe statistically significant support for the hypothesized effects of perceived DA frequency on attributions to self $\left(\mathrm{H}_{5 \mathrm{a}} ; b=-.06, p<.01\right)$, the supplier $\left(\mathrm{H}_{5 \mathrm{~b}} ; b=.18, p<.01\right)$ and external environment $\left(\mathrm{H}_{5} ; b=-.12, p<.01\right)$.

\subsection{Interactive Effect of Interdependence Structure and Prior Relationship Quality on Causal Attributions \\ $\mathrm{H}_{6}$ is partially supported. As predicted, the positive effect of total dependence on causal attributions to self $\left(\mathrm{H}_{6 a} ; b=.04, p<.02\right)$ is amplified for higher levels of prior relationship quality. We also found statistically significant support for the posited negative effect of the interaction term on attributions to the supplier $\left(\mathrm{H}_{6 \mathrm{~b}} ; b=-.05, p<.04\right)$. The effect of the interaction between}


total dependence and prior relationship quality on causal attribution to the external environment $\left(\mathrm{H}_{6 \mathrm{c}} ; b=-.06, p<.04\right)$ is statistically significant but in a negative direction. The latter suggests that the positive effect of total dependence on retailer's causal attribution to the external environment is dampened (rather than amplified, as we hypothesized) for higher levels of prior relationship quality - it would appear that when total dependence and prior relationship quality are high, the retailer is more likely to make the causal attribution to itself and less likely to make it to the supplier or, in contrast to our hypothesis, the external environment. This finding raises the possibility that, for a firm, there may be benefits from attributing to the blame to oneself that go beyond the benefits of not attributing the blame to the partner.

\subsection{Interactive Effect of Destructive Act Dimensions and Prior Relationship Quality on Causal Attributions}

We find partial support for $\mathrm{H}_{8}$ and $\mathrm{H}_{9}$. As hypothesized in $\mathrm{H}_{8}$, the negative effect of DA intensity on causal attributions to self $\left(\mathrm{H}_{8 \mathrm{a}} ; b=-.05, p<.05\right)$ and the positive effect of DA intensity on causal attributions to the supplier $\left(\mathrm{H}_{8 \mathrm{~b}} ; b=.08, p<.01\right)$ are amplified for higher levels of prior relationship quality. We find no support for the hypothesized effect of the interaction term on causal attributions to the external environment $\left(\mathrm{H}_{8 \mathrm{c}} ; b=.02, p<.3\right)$. As posited in $\mathrm{H}_{9}$, the negative effect of DA frequency on causal attributions to the external environment $\left(\mathrm{H}_{9 \mathrm{c}} ; b=-.08, p<.01\right)$ is greater for higher levels of prior relationship quality. We observe no empirical support for the hypothesized effect of the interaction term on causal attributions to self $\left(\mathrm{H}_{9 \mathrm{a}} ; b=.008, p<.4\right)$ and the supplier $\left(\mathrm{H}_{9 b} ; b=-.03, p<.2\right)$.

\section{Discussion}

Rapidly shifting and evolving business environments and technologies can create multiple opportunities and threats for firms. Firms may undertake actions to realize these 
opportunities and safeguard against these threats - for example, adding a new channel to the distribution channel system. The importance of studying DAs in distribution channels is underlined by three factors - first, the increasing frequency with which firms have been undertaking these acts; second, channel member responses to the act (and the significant consequences of these responses for relational outcomes and performance in the distribution channel); and third, the implications for what firms can proactively do (before and immediately after the DAs) to mitigate the adverse consequences of these acts for their channel relationships.

\subsection{Theoretical Contributions}

Much of the extant distribution channels research on DAs has focused on their consequences - how the act has hurt existing channel members and the consequences of this damage (e.g., Ganesan et al., 2010). Whether the impacted channel member attributes the cause of the DA to relatively benign (e.g., itself or the external environment) or relatively damaging (the firm that initiates the act) sources has significant ramifications for interorganizational conflict and conflict responses (Kaufmann \& Stern, 1988), continuity (Wang et al., 2018), relationship quality and performance (Hibbard et al., 2001) and the behavior of the firm (Frazier, 1983), In view of this, the relative paucity of scholarly insights on antecedents of causal attributions for DAs represents a notable gap in the distribution channels literature. We address this gap by using a behavioral-based approach and incorporating insights from interdependence theory and attribution theory to develop and empirically assess a theoretical framework of antecedents of causal attributions for DAs in distribution channels.

Our theoretical framework posits direct effects of the pre-act interdependence structure of the supplier-retailer relationship (in terms of total dependence and dependence asymmetry), pre- 
act relationship quality and dimensions of the DA (in terms of retailer-perceived intensity and frequency of DAs) on causal attributions made by the retailer for a DA initiated by the supplier. Additionally, we posit interactions, where pre-act relationship quality amplifies the effects of interdependence structure and DA dimensions on the causal attributions.

Our empirical findings, based on moderated spline regression analyses of dyadic, multiple informant survey data collected from the distribution channel of a Fortune 500 company, reveal some support for our hypotheses. First, we find that higher levels of total dependence are associated with significantly lower retailer attributions of the DA to the supplier. Second, as dependence asymmetry increases, a retailer is less likely to make relatively benign causal attributions (to itself or the external environment) and, when the supplier is relatively dependent, a retailer is more likely to attribute the DA to the supplier. Third, we also find that causal attributions made by retailers are influenced by the perceived intensity and frequency of DAs - when the intensity or frequency is high, a retailer is more likely to make damaging causal attributions and less likely to make benign ones. Finally, we find evidence for the key role played by prior relationship quality - it reduces causal attribution to self or the supplier as well as amplifies the effects of other constructs (total dependence and the intensity and frequency of DAs) on some causal attributions.

\subsection{Managerial Implications}

Our findings have practical implications for firms that are faced with a business imperative to undertake DAs but need to limit the damage caused by them to extant channel relationships and corresponding performance outcomes. By understanding the antecedents of causal attributions made by existing channel members, a firm can mitigate their harmful 
consequences in three ways. First, it can attempt to dampen the perceived intensity and frequency of DAs it may need to undertake. Second, it can develop its relationships with channel partners in a manner that buffers the relationships from the damaging consequences of adverse attributions - this implies developing distribution channel relationships with relatively high and symmetric dependence and high relationship quality. Finally, it can identify vulnerable

distribution channel relationships (that is, those with relatively low total and/or more asymmetric dependence and/or low relationship quality) and proactively undertake tactical interventions to influence the channel partners into making benign causal attributions as well as to ameliorate harmful consequences of adverse causal attributions on relationship outcomes and performance.

\subsection{Limitations and Future Research}

Our work has some limitations, but many of them can serve as a platform for future research that augments the distribution channels literature as well as refines and strengthens our managerial implications.

First, although we use cross-sectional survey data, we undertook steps to overcome a number of problems associated with cross-sectional, survey data-based research. We used informants from both sides of the dyad, carefully designed the survey instrument as well as used derived measures (rather than directly collected measures) for key constructs in order to control for the common method bias problem. Additionally, we drew on established and rigorous theoretical perspectives to develop the causal logic for our hypotheses. Nevertheless, there is room to further enhance the strength of causal inferences by augmenting this study with longitudinal and experimental research. 
Second, in empirically examining DAs, we focused on a specific act or episode that was the most destructive action as perceived by the retailer. This is consistent with the use of the critical incident technique in channels research (e.g., Harmeling et al., 2015). Future research can enrich the theoretical and empirical understanding of DAs in distribution channels by conceptualizing and measuring a broader and more general measure of destructive activity.

Third, we draw on multiple theoretical perspectives (e.g., interdependence theory, attribution theory) to develop our conceptual framework. There may be room to enrich our framework by incorporating other theoretical viewpoints that are widely used in distribution channels research - for example, incorporating fairness and equity perspectives to better understand antecedents and consequences of causal attributions for DAs may be a particularly fertile avenue for future research.

Fourth, our research focuses on locus of causality attributions, in keeping with much of the extant channels research (e.g., Hibbard et al., 2001; Scheer \& Stern, 1992). Recently, researchers in marketing have examined the stability and controllability dimensions (Weiner, 1985) of causal attributions - e.g., Wang et al (2018) examine consequences of stability, controllability and locus of causality attributions. Future research could enhance our understanding of causal attributions by examining antecedents of the stability and controllability dimensions of causal attributions.

Fifth, our empirical findings and revealed support for most of our hypotheses. However, for a few hypotheses, the support was partial; only H2 (for Supplier Relative Dependence), H4 and H5 were completely supported. One possible explanation for the presence of a few results which were statistically nonsignificant could be the use of non-comparative scales for measuring 
attributions to self, partner and external environment. It is possible that, for some hypotheses, we see statistically significant results only for the causal attribution most impacted by the antecedent being examined. An alternative approach could be to use comparative scales for measuring attributions to self, partner and external environment - this could be a direction for future research.

Finally, we focus on the context where an upstream firm (supplier) initiates the destructive act that negatively affects a downstream firm (retailer). Future research could examine the robustness of our theoretical framework for examining DAs that were initiated by large and powerful retailers (e.g., Wal-Mart and Amazon) and affected upstream suppliers. 


\section{REFERENCES}

Agnew, C. R., Van Lange, P. A., Rusbult, C. E., \& Langston, C. A. (1998). Cognitive interdependence: Commitment and the mental representation of close relationships. Journal of Personality and Social Psychology, 74(4), 939-954.

Aiken, L. S., \& West, S. G. (1991). Multiple Regression: Testing and Interpreting Interactions. Sage.

Anand, P. (1987). Inducing franchisees to relinquish control: An attribution analysis. Journal of Marketing Research, 24(2), 215-221.

Anand, P., \& Stern, L. W. (1985). A sociopsychological explanation for why marketing channel members relinquish control. Journal of Marketing Research, 22(4), 365-376.

Anderson, J. C., \& Gerbing, D. W. (1988). Structural equation modeling in practice: A review and recommended two-step approach. Psychological Bulletin, 103(3), 411-423.

Anderson, J. C., \& Narus, J. A. (1990). A model of distributor firm and manufacturer firm working partnerships. Journal of Marketing, 54(1), 42-58.

Anderson, E., \& Weitz, B. (1989). Determinants of continuity in conventional industrial channel dyads. Marketing Science, 8(4), 310-323.

Antia, K. D., \& Frazier, G. L. (2001). The severity of contract enforcement in interfirm channel relationships. Journal of Marketing, 65(4), 67-81.

Bagozzi, R. P. (1984). A prospectus for theory construction in marketing. Journal of Marketing, 48(1), 11-29.

Baumeister, R. F., Bratslavsky, E., Finkenauer, C., \& Vohs, K. D. (2001). Bad is stronger than good. Review of General Psychology, 5(4), 323-370.

Bollen, K. A. (1990). Overall fit in covariance structure models: two types of sample size effects. Psychological Bulletin, 107(2), 256-259.

Bradbury, T. N., \& Fincham, F. D. (1990). Attributions in marriage: review and critique. Psychological Bulletin, 107(1), 3-33.

Buchanan, L. (1992). Vertical trade relationships: the role of dependence and symmetry in attaining organizational goals. Journal of Marketing Research, 29(1), 65-75.

Churchill Jr, G. A. (1979). A paradigm for developing better measures of marketing constructs. Journal of Marketing Research, 16(1), 64-73.

Dant, R. P., \& Schul, P. L. (1992). Conflict resolution processes in contractual channels of distribution. Journal of Marketing, 56(1), 38-54.

Dwyer, F. R., \& Oh, S. (1987). Output sector munificence effects on the internal political economy of marketing channels. Journal of Marketing Research, 24(4), 347-358.

Emerson, R. M. (1962). Power-dependence relations. American Sociological Review, 27(1), 3141.

Frazier, G. L. (1983). Interorganizational exchange behavior in marketing channels: a broadened perspective. Journal of Marketing, 47(4), 68-78. 
Frazier, G. L., Gill, J. D., \& Kale, S. H. (1989). Dealer dependence levels and reciprocal actions in a channel of distribution in a developing country. Journal of Marketing, 53(1), 50-69.

Fuller, C. M., Simmering, M. J., Atinc, G., Atinc, Y., \& Babin, B. J., Common methods variance detection in business research. Journal of Business Research, 69(8), 2016, 3192-3198.)

Ganesan, S. (1994). Determinants of long-term orientation in buyer-seller relationships. Journal of Marketing, 58(2), 1-9.

Ganesan, S., Brown, S. P., Mariadoss, B. J., \& Ho, H. (2010). Buffering and amplifying effects of relationship commitment in business-to-business relationships. Journal of Marketing Research, 47(2), 361-373.

Ganesan, S., George, M., Jap, S., Palmatier, R. W., \& Weitz, B. (2009). Supply chain management and retailer performance: emerging trends, issues, and implications for research and practice. Journal of Retailing, 85(1), 84-94.

Gerbing, D. W., \& Anderson, J. C. (1988). An updated paradigm for scale development incorporating unidimensionality and its Assessment. Journal of Marketing Research, 25(2), 186-192.

Harmeling, C. M., Palmatier, R. W., Houston, M. B., Arnold, M. J., \& Samaha, S. A. (2015). Transformational relationship events. Journal of Marketing, 79(5), 39-62.

Heide, J. B. (1994). Interorganizational governance in marketing channels. Journal of Marketing, $58(1), 71-85$.

Hibbard, J. D., Kumar, N., \& Stern, L. W. (2001). Examining the impact of destructive acts in marketing channel relationships. Journal of Marketing Research, 38(1), 45-61.

Jap, S. D., Manolis, C., \& Weitz, B. A. (1999). Relationship quality and buyer-seller interactions in channels of distribution. Journal of Business Research, 46(3), 303-313.

Jones, E. E., \& Davis, K. E. (1965). From acts to dispositions: The attribution process in person perception. Advances in Social Psychology, 2(21), 9-66.

Kaufmann, P. J., \& Stern, L. W. (1988). Relational exchange norms, perceptions of unfairness, and retained hostility in commercial litigation. Journal of Conflict Resolution, 32(3), 534552.

Kelley, H. H. (1967). Attribution theory in social psychology. In Nebraska Symposium on Motivation. University of Nebraska Press.

Kelley, H. H., \& Michela, J. L. (1980). Attribution theory and research. Annual Review of Psychology, 31(1), 457-501.

Kim, S. K., Hibbard, J. D., \& Swain, S. D. (2011). Commitment in Marketing Channels: Mitigator or Aggravator of the Effects of Destructive Acts? Journal of Retailing, 87(4), 521539.

Kumar, N. (2005). The power of power in supplier-retailer relationships. Industrial Marketing Management, 34(8), 863-866.

Kumar, N., Scheer, L. K., \& Steenkamp, J. B. E. (1995). The effects of perceived interdependence on dealer attitudes. Journal of Marketing Research, 32(3), 348-356. 
Kumar, N., Scheer, L. K., \& Steenkamp, J. B. E. (1998). Interdependence, punitive capability, and the reciprocation of punitive actions in channel relationships. Journal of Marketing Research, 35(2), 225-235.

Kumar, N., Stern, L. W., \& Anderson, J. C. (1993). Conducting interorganizational research using key informants. Academy of Management Journal, 36(6), 1633-1651.

Lawler, E. J., \& Bacharach, S. B. (1987). Comparison of dependence and punitive forms of power. Social Forces, 66(2), 446-462.

Lawler, E. J., Ford, R., \& Blegen, M. A. (1988). Coercive capability in conflict: A test of bilateral deterrence versus conflict spiral theory. Social Psychology Quarterly, 51(2), 93-107.

Lawler, E. J., \& Yoon, J. (1996). Commitment in exchange relations: Test of a theory of relational cohesion. American Sociological Review, 61(1), 89-108.

Lusch, R. F., \& Brown, J. R. (1996). Interdependency, contracting, and relational behavior in marketing channels. Journal of Marketing, 60(4), 19-38.

MacKenzie, S. B., \& Podsakoff, P. M. (2012). Common method bias in marketing: causes, mechanisms, and procedural remedies. Journal of Retailing, 88(4), 542-555.

Marsh, L. C., \& Cormier, D. R. (2001). Spline regression models (Vol. 137). Sage.

Mohr, J. J., \& Nevin, J. R. (1990). Communication strategies in marketing channels: A theoretical perspective. Journal of Marketing, 54(4), 36-51.

Murray, S. L., Holmes, J. G., \& Griffin, D. W. (1996). The benefits of positive illusions: Idealization and the construction of satisfaction in close relationships. Journal of Personality and Social Psychology, 70(1), 79-98.

Netter, J., Wasserman, W., \& Kutner, M. H. (1990). Applied linear statistical models. Irwin Inc.

Park, B., Park, H., \& Ramanujam, R. (forthcoming). Tua Culpa: When an Organization Blames its Partner for Failure in a Shared Task. Academy of Management Review.

Podsakoff, P. M., MacKenzie, S. B., Lee, J. Y., \& Podsakoff, N. P., Common method biases in behavioral research: A critical review of the literature and recommended remedies. Journal of Applied Psychology, 88(5), 2003, 879-903. )

Podsakoff, P. M., MacKenzie, S. B., \& Podsakoff, N. P. (2012). Sources of method bias in social science research and recommendations on how to control it. Annual Review of Psychology, 63(1), 539-569.

Podsakoff, P. M., \& Organ, D. W. (1986). Self-reports in organizational research: Problems and prospects. Journal of Management, 12(4), 531-544.

Rossiter, J. R. (2002). The C-OAR-SE procedure for scale development in marketing. International Journal of Research in Marketing, 19(4), 305-335.

Rusbult, C. E., \& Van Lange, P. A. (2003). Interdependence, interaction, and relationships. Annual Review of Psychology, 54(1), 351-375.

Rusbult, C. E., Van Lange, P. A., Wildschut, T., Yovetich, N. A., \& Verette, J. (2000). Perceived superiority in close relationships: why it exists and persists. Journal of Personality and Social Psychology, 79(4), 521-545. 
Scheer, L. K., Miao, C. F., \& Palmatier, R. W. (2015). Dependence and interdependence in marketing relationships: meta-analytic insights. Journal of the Academy of Marketing Science, 43(6), 694-712.

Scheer, L. K., \& Stern, L. W. (1992). The effect of influence type and performance outcomes on attitude toward the influencer. Journal of Marketing Research, 29(1), 128-142.

Selnes, F., \& Gønhaug, K. (2000). Effects of supplier reliability and benevolence in business marketing. Journal of Business Research, 49(3), 259-271.

Thibaut, J. W., \& Riecken, H. W. (1955). Some Determinants and Consequences of the Perception of Social Causality. Journal of Personality, 24(2), 113-133.

Van Bruggen, G. H., Kacker, M., \& Nieuwlaat, C. (2005). The impact of channel function performance on buyer-seller relationships in marketing channels. International Journal of Research in Marketing, 22(2), 141-158.

Van Bruggen, G. H., Lilien, G. L., \& Kacker, M. (2002). Informants in organizational marketing research: Why use multiple informants and how to aggregate responses. Journal of Marketing Research, 39(4), 469-478.

Wang, Q., \& Jap, S. (2017). Benevolent dictatorship and buyer-supplier exchange. Journal of Business Research, 78, 204-216.

Wang, Q., Cheng, L., Craighead, C. W., \& Li, J. J. (2018). Who or What Gets the Blame? The Role of Causal Attribution in Supply Chain Disruption Resolution. Working paper.

Watson, G. F., Worm, S., Palmatier, R. W., \& Ganesan, S. (2015). The Evolution of Marketing Channels: Trends and Research Directions. Journal of Retailing, 91(4), 546-568.

Weiner, B. (1985). An attributional theory of achievement motivation and emotion. Psychological review, 92(4), 548.

Westberg, K., Stavros, C., \& Wilson, B. (2011). The impact of degenerative episodes on the sponsorship B2B relationship: Implications for brand management. Industrial Marketing Management, 40(4), 603-611.

Williamson, O. E. (1985). The Economic Institutions of Capitalism. Simon and Schuster. 


\section{Appendix A}

Measurement items

Eliciting the Destructive Act (Hibbard, Kumar, \& Stern, 2001)

We are interested if any of the actions listed below affected the way you run your dealership. Please read the following statements and keep in mind that we would like you to select the action that has had the most negative effect on your dealership.

Check YES if you agree the action had a negative impact on your dealership.

Check NO if the action did not happen, or if it happened, it did not have a negative impact on your dealership.

Yes No

1. [The supplier's] decision to sell through [the name of the mass merchandiser].

2. Within the past two years, [the supplier] added another dealer to your territory.

3. Within the past two years, [the supplier] has pulled a product from your line

4. [The supplier's] decision to use an outside firm to handle [the supplier's] credit card.

[Retailers were also given the opportunity to write in some other supplier action that had a negative effect on them. Subsequently, retailers were asked to identify the supplier' action that had the most negative effect on their dealership. Then they were instructed; "Now we would like you to answer several questions regarding the SPECIFIC negative act you have just identified."]

Destructive Act Intensity (Hibbard et al., 2001)

When you first learned of it, how damaging did your firm initially view this act by [the supplier]?

Destructive Act Frequency (New Scale)

Within the past two years, how often have negative actions of this type happened in your relationship with [the supplier]?

Causal Attributions (Adapted from Bradbury \& Fincham, 1990)

Again, keeping in mind the SPECIFIC NEGATIVE ACTION that you previously identified, answer the following set of questions. Please reflect on the extent to which you believe each of the following reasons contributed to [the supplier's] actions.

Self

Our firm does not hold [the supplier] responsible for the act, because in some ways we provoked them.

We bear most of the blame for [the supplier's] action, since our past behavior toward them contributed to it.

We were to blame for [the supplier's] decision to do what they did.

Partner

[The supplier's] act was taken because they tend to look out for their own interests, not ours.

[The supplier] is self-centered, and this accounts for their action.

[The supplier's] act was intended to benefit them, not us.

External Environment

Competitive conditions forced [the supplier] to take this action. 
[The supplier's] behavior was understandable, given the market conditions in our area.

The current environment in the industry was responsible for [the suppliers] action.

Prior Relationship Quality (Adapted from Dwyer \& Oh 1987; Anderson \& Narus, 1990)

Prior Trust

Please circle the number that you feel best represents your feelings toward [the supplier] PRIOR to the incident.

We could rely on [the supplier] to keep promises they made to us.

We could count on [the supplier] to be sincere in their dealings with our firm.

[The supplier] was a company that stood by its word.

Pre-act Commitment

PRIOR to the incident, we remained a [the supplier] dealer because ...

We felt like "part of the [the supplier] family."

We were attracted to the things [the supplier] stood for as a company.

We genuinely enjoyed our relationship with [the supplier].

Socialization

[The supplier's] advice when our firm was just starting out helped us become an effective business.

[The supplier] had many excellent procedures to initiate a dealer into its dealer network.

When we initially became [the supplier] dealer, [the supplier] went out of their way to help us understand [the supplier's] way of doing business.

Total Dependence and Dependence Asymmetry* (Adapted from Kumar, Scheer, \& Steenkamp, 1995)

Retailer's Dependence

Compared to other parts of our business, (such as [several lines listed]), our relationship with [the supplier] is central to the financial well-being of our firm.

Having [the supplier] as a supplier is critical to achieving our organizational goals.

Our firm would survive very well without [the supplier]. (R)

Supplier's Dependence [measured from supplier's side]

Our relationship with this dealer is critical to [our firm] meeting their unit goals in this area.

Our district would suffer a significant drop in revenue if the relationship with this dealer dissolved.

* Retailer and supplier dependence items were used to calculate measures of total dependence and dependence asymmetry.

Notes: All items were measured using seven-point Likert-type scales unless otherwise noted. (R) denotes items that were reverse coded. [The supplier] is used to disguise the name of the supplier/manufacturer.

Note: Retailers responded to all measurement items (Appendix A) except 'Supplier's Dependence' elicited from the supplier's side. 
Table 1

Correlations and descriptive statistics.

\begin{tabular}{|c|c|c|c|c|c|c|c|c|c|}
\hline Constructs & 1 & 2 & 3 & 4 & 5 & 6 & 7 & 8 & 9 \\
\hline 1. Supplier Dependence & .792 & & & & & & & & \\
\hline 2. Retailer Dependence & $.162^{* *}$ & .680 & & & & & & & \\
\hline 3. Prior Relationship Quality & $.164^{* *}$ & $.340^{* *}$ & .738 & & & & & & \\
\hline 4. Destructive Act Intensity & -.015 & $-.095^{*}$ & .01 & N.A. & & & & & \\
\hline 5. Destructive Act Frequency & -.073 & $-.201^{* *}$ & $-.130^{* *}$ & $.282^{* *}$ & N.A. & & & & \\
\hline 6. Self-attribution & .026 & .054 & $-.075^{*}$ & $-.219^{* *}$ & $-.159^{* *}$ & .654 & & & \\
\hline 7. Supplier-attribution & $-.125^{* *}$ & $-.226^{* *}$ & $-.140^{* *}$ & $.276^{* *}$ & $.329^{* *}$ & $-.246^{* *}$ & .702 & & \\
\hline 8. External Environment-attribution & .056 & $.080^{*}$ & $.075^{*}$ & $-.360^{* *}$ & $-.212^{* *}$ & $.265^{* *}$ & $-.272^{* *}$ & .728 & \\
\hline 9. Age of relationship ${ }^{a}$ & $.155^{* *}$ & .063 & $.121^{* *}$ & .043 & -.002 & $-.099^{* *}$ & .028 & -.033 & N.A. \\
\hline Mean & 5.04 & 4.04 & 5.27 & 5.37 & 3.61 & 1.65 & 5.57 & 3.25 & 168.96 \\
\hline Std. Dev. & 1.51 & 1.32 & 1.04 & 1.27 & 1.86 & 0.91 & 1.26 & 1.5 & 112.38 \\
\hline Number of items & 2 & 3 & 9 & 1 & 1 & 3 & 3 & 3 & 1 \\
\hline Construct reliability & 0.7 & 0.71 & .70 & N.A. & N.A. & 0.63 & 0.73 & 0.79 & N.A. \\
\hline \multicolumn{10}{|l|}{ Goodness-of-fit statistics } \\
\hline$\chi^{2}$ & $p$ & & \multicolumn{2}{|c|}{ RMSEA } & \multicolumn{2}{|l|}{$\mathrm{CIF}$} & \multicolumn{2}{|l|}{ TLI } & NNFI \\
\hline 328.881 & .00 & & \multicolumn{2}{|l|}{.036} & \multicolumn{2}{|l|}{.967} & \multicolumn{2}{|l|}{.965} & .922 \\
\hline
\end{tabular}

${ }^{a}$ Number of months the retailer has direct contact with the supplier.

N.A. = not applicable.

Note: Bold diagonal values are the square roots of AVEs for the factors and off-diagonal values are the correlation coefficients among the factors.

${ }^{*} p<.05$.

$p<.01$.

Note: All correlations are based on 699 observations except for supplier dependence correlations with other variables that are based on 429 observations. 
Table 2

Results of regression analyses

\begin{tabular}{|c|c|c|c|c|c|c|c|c|c|}
\hline \multirow[b]{2}{*}{ Independent Variables } & \multicolumn{3}{|c|}{ Self } & \multicolumn{3}{|c|}{ Supplier } & \multicolumn{3}{|c|}{ External Environment } \\
\hline & Hypothesis & Equation 1 & Equation 2 & Hypothesis & Equation 1 & Equation 2 & Hypothesis & Equation 1 & Equation 2 \\
\hline & & $\begin{array}{l}\text { Coefficient } \\
\text { (Std. Error) }\end{array}$ & $\begin{array}{l}\text { Coefficient } \\
\text { (Std. Error) }\end{array}$ & & $\begin{array}{l}\text { Coefficient } \\
\text { (Std. Error) }\end{array}$ & $\begin{array}{l}\text { Coefficient } \\
\text { (Std. Error) }\end{array}$ & & $\begin{array}{l}\text { Coefficient } \\
\text { (Std. Error) }\end{array}$ & $\begin{array}{l}\text { Coefficient } \\
\text { (Std. Error) }\end{array}$ \\
\hline Age of relationship & & $\begin{array}{l}0.000 \\
(0.000)\end{array}$ & $\begin{array}{l}0.000 \\
(0.000)\end{array}$ & & $\begin{array}{l}0.000 \\
(0.001)\end{array}$ & $\begin{array}{l}0.000 \\
(0.001)\end{array}$ & & $\begin{array}{l}0.000 \\
(0.001)\end{array}$ & $\begin{array}{l}0.000 \\
(0.001)\end{array}$ \\
\hline Total Dependence (TD) & $\mathrm{H}_{1 \mathrm{a}}:(+)$ & $\begin{array}{l}0.016 \\
(0.022)\end{array}$ & $\begin{array}{l}0.018 \\
(0.022)\end{array}$ & $\mathrm{H}_{1 \mathrm{~b}}:(-)$ & $\begin{array}{l}-0.087^{\text {**** }} \\
(0.030)\end{array}$ & $\begin{array}{l}-0.084^{* * *} \\
(0.030)\end{array}$ & $\mathrm{H}_{1 \mathrm{c}}:(+)$ & $\begin{array}{l}0.021 \\
(0.036)\end{array}$ & $\begin{array}{l}0.020 \\
(0.036)\end{array}$ \\
\hline Retailer Relative Dependence (DRD) & $\mathrm{H}_{2 \mathrm{a}}:(-)$ & $\begin{array}{l}-0.073^{*} \\
(0.047)\end{array}$ & $\begin{array}{l}-0.068^{*} \\
(0.047)\end{array}$ & $\mathrm{H}_{2 \mathrm{~b}}:(+)$ & $\begin{array}{l}0.056 \\
(0.064)\end{array}$ & $\begin{array}{l}0.058 \\
(0.064)\end{array}$ & $\mathrm{H}_{2 \mathrm{c}}:(-)$ & $\begin{array}{l}-0.126^{* *} \\
(0.076)\end{array}$ & $\begin{array}{l}-0.126^{* *} \\
(0.076)\end{array}$ \\
\hline Supplier Relative Dependence (SRD) & $\mathrm{H}_{2 \mathrm{a}}:(-)$ & $\begin{array}{l}-0.102^{* *} \\
(0.048)\end{array}$ & $\begin{array}{l}-0.087^{* *} \\
(0.049)\end{array}$ & $\mathrm{H}_{2 b}:(+)$ & $\begin{array}{l}0.095^{*} \\
(0.065)\end{array}$ & $\begin{array}{l}0.100^{*} \\
(0.067)\end{array}$ & $\mathrm{H}_{2 \mathrm{c}}:(-)$ & $\begin{array}{l}-0.127^{* *} \\
(0.077)\end{array}$ & $\begin{array}{l}-0.110^{*} \\
(0.079)\end{array}$ \\
\hline Prior Relationship Quality (PRQ) & $\mathrm{H}_{3 \mathrm{a}}:(-)$ & $\begin{array}{l}-0.076^{* *} \\
(0.043)\end{array}$ & $\begin{array}{l}-0.082^{* *} \\
(0.044)\end{array}$ & $\mathrm{H}_{3 \mathrm{~b}}:(-)$ & $\begin{array}{l}-0.124^{* *} \\
(0.058)\end{array}$ & $\begin{array}{l}-0.125^{* *} \\
(0.059)\end{array}$ & $\mathrm{H}_{3 \mathrm{c}}:(+)$ & $\begin{array}{l}0.055 \\
(0.069)\end{array}$ & $\begin{array}{l}0.081 \\
(0.070)\end{array}$ \\
\hline Destructive Act Intensity (DAI) & $\mathrm{H}_{4 \mathrm{a}}:(-)$ & $\begin{array}{l}-0.091^{* * *} \\
(0.029)\end{array}$ & $\begin{array}{l}-0.083^{* * *} \\
(0.029)\end{array}$ & $\mathrm{H}_{4 \mathrm{~b}}:(+)$ & $\begin{array}{l}0.096^{* * *} \\
(0.039)\end{array}$ & $\begin{array}{l}0.082^{* * *} \\
(0.039)\end{array}$ & $\mathrm{H}_{4 \mathrm{c}}:(-)$ & $\begin{array}{l}-0.196^{* * *} \\
(0.046)\end{array}$ & $\begin{array}{l}-0.195^{* * *} \\
(0.046)\end{array}$ \\
\hline Destructive Act Frequency (DAF) & $\mathrm{H}_{5 \mathrm{a}}:(-)$ & $\begin{array}{l}-0.059^{\text {**** }} \\
(0.024)\end{array}$ & $\begin{array}{l}-0.057^{* * *} \\
(0.024)\end{array}$ & $\mathrm{H}_{5 b}:(+)$ & $\begin{array}{l}0.182^{* * * *} \\
(0.033)\end{array}$ & $\begin{array}{l}0.177^{* * *} \\
(0.033)\end{array}$ & $\mathrm{H}_{5 \mathrm{c}}:(-)$ & $\begin{array}{l}-0.125^{* * *} \\
(0.038)\end{array}$ & $\begin{array}{l}-0.122^{* * *} \\
(0.039)\end{array}$ \\
\hline $\mathrm{PRQ} * \mathrm{TD}$ & $\mathrm{H}_{6 \mathrm{a}} \mathrm{a}(+)$ & & $\begin{array}{l}0.043^{* *} \\
(0.019)\end{array}$ & $\mathrm{H}_{6 \mathrm{~b}}:(-)$ & & $\begin{array}{l}-0.047^{* *} \\
(0.026)\end{array}$ & $\mathrm{H}_{6 \mathrm{c}}:(+)$ & & $\begin{array}{l}-0.056^{* *} \\
(0.030)\end{array}$ \\
\hline PRQ * DRD & $\mathrm{H}_{7 \mathrm{a}} \mathrm{a}(-)$ & & $\begin{array}{l}0.030 \\
(0.048)\end{array}$ & $\mathrm{H}_{7 \mathrm{~b}}:(+)$ & & $\begin{array}{l}-0.046 \\
(0.065)\end{array}$ & $\mathrm{H}_{7 \mathrm{c}}:(-)$ & & $\begin{array}{l}-0.012 \\
(0.077)\end{array}$ \\
\hline $\mathrm{PRQ} * \mathrm{SRD}$ & $\mathrm{H}_{7 \mathrm{a}}:(-)$ & & $\begin{array}{l}0.026 \\
(0.044)\end{array}$ & $\mathrm{H}_{7 \mathrm{~b}}:(+)$ & & $\begin{array}{l}0.049 \\
(0.059)\end{array}$ & $\mathrm{H}_{7 \mathrm{c}}:(-)$ & & $\begin{array}{l}-0.014 \\
(0.070)\end{array}$ \\
\hline PRQ * DAI & $\mathrm{H}_{8 \mathrm{a}}:(-)$ & & $\begin{array}{l}-0.045^{* *} \\
(0.027)\end{array}$ & $\mathrm{H}_{8 \mathrm{~b}}:(+)$ & & $\begin{array}{l}0.084^{* * * *} \\
(0.036)\end{array}$ & $\mathrm{H}_{8 \mathrm{c}}:(-)$ & & $\begin{array}{l}0.023 \\
(0.043)\end{array}$ \\
\hline $\mathrm{PRQ} * \mathrm{DAF}$ & $\mathrm{H}_{9 \mathrm{a}}:(-)$ & & $\begin{array}{l}0.008 \\
(0.021)\end{array}$ & $\mathrm{H}_{9 b}:(+)$ & & $\begin{array}{l}-0.027 \\
(0.029)\end{array}$ & $\mathrm{H}_{9 \mathrm{c}}:(-)$ & & $\begin{array}{l}-0.082^{* * *} \\
(0.034)\end{array}$ \\
\hline Adjusted $\mathrm{R}^{2}$ & & 0.052 & 0.057 & & 0.135 & 0.145 & & 0.083 & 0.093 \\
\hline
\end{tabular}

Note: Coefficients are unstandardized beta values. Numbers in parentheses are standard error values.

One sided $\mathrm{p}$ values: $* \mathrm{p}<.1 . ; * * \mathrm{p}<.05$. ; *** $\mathrm{p}<.01$ 


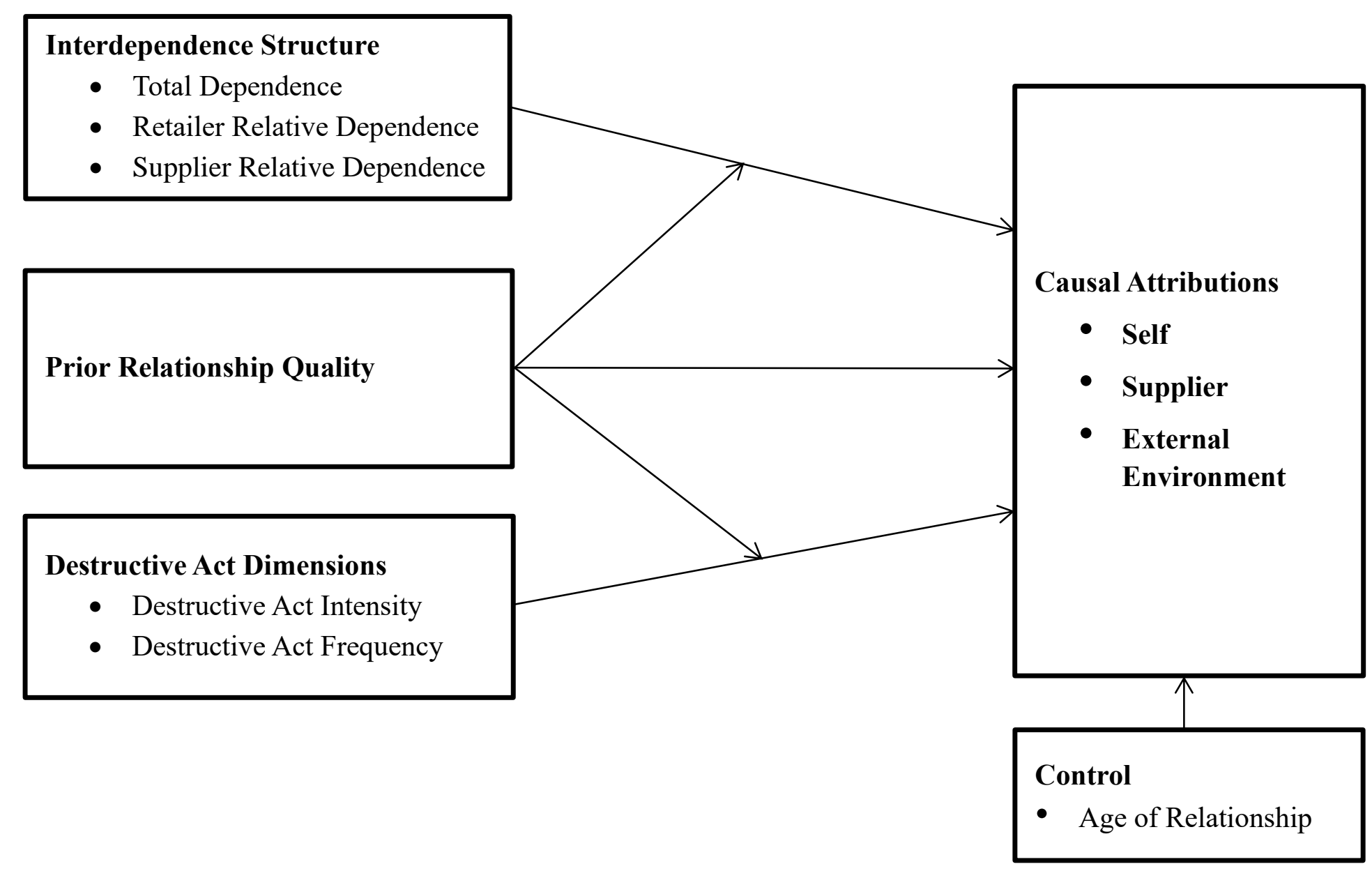

Fig. 1. Conceptual framework. 